\title{
Substantiation of Initial-I Stage of Generalized Periodontitis Complex Treatment Choice Among Medical University Students According to Indicators' Dynamics Changes of Oral Cavity Prooxidant-antioxidant System
}

\author{
Tetiana Pavliuk, Mykola Rozhko, Panchak Oksana
}

\begin{abstract}
According to the results of epidemiological studies, the spread of periodontal tissue diseases has tendency to increase, despite recent decades' significant achievements in dentistry. Studies of periodontal tissue diseases pathogenesis have found that oxygen-dependent production of reactive oxygen species (ROS) and antioxidant activity are involved in the pathogenic mechanism of the disease. ROS are highly toxic and can induce lipid peroxidation (LPO). Researchers have shown increased levels of LPO with generalized periodontitis (GP). "Noofen" is one of the drugs that normalizes the processes of LPO and shows positive effect in GP treatment. That is why in advanced complex treatment of generalized periodontitis of initial-I stage, we've used this pill.

The objective of the study was to analyze the efficiency of nootropic medicine "Noofen" usage in suggested initial-I stage of generalized periodontitis treatment, taking into account the dynamics of oral fluid prooxidant and antioxidant indicators among students with high level of emotional sensitivity.

Materials and methods. A study of $2^{\text {nd }}$ year students (174) of Ivano-Frankivsk National Medical University were questioned in order to determine the level of individual emotional states (anxiety, frustration, aggression and rigidity) according to the method of $\mathrm{H}$. Eysenck. Of those who have experienced increased and high level of emotional sensitivity to various stressors and situations, we have selected 50 students with initial-I stage of generalized periodontitis. To determine the efficiency of treatment, two groups were formed: observation (group I) and comparison (group II). Each group consisted of 25 individuals who were treated and monitored dynamically during the year. The condition of oral cavity prooxidant system was determined by the level of malondialdehyde (MDA) and diene conjugates (DC). To study the state of the antioxidant protection system, the activity of superoxide dismutase (SOD), glutathione-S-transferase (G-ST) and glutathione peroxidase (GPO) were determined. The advanced treatment, which included oral rinsing with "Octenisept" solution, dissolving of tablets "Lizak", intake of medicine "Noofen" and vitamin-microelement complex "Vita-Supradin Active".

Conclusions. The results of the performed treatment indicate that the use of advanced therapy of GP is significantly more effective, confirmed by prooxidant-antioxidant system parameters of oral fluid in the long term, compared with traditional treatment.
\end{abstract}

\section{Keywords}

generalized periodontitis; prooxidant-antioxidant system; oxidative stress; medical students

Ivano-Frankivsk National Medical University, Ivano-Frankivsk, Ukraine

*Corresponding author: pavliuktv@gmail.com

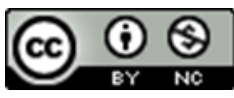




\section{Problem statement and analysis of the latest research}

According to epidemiological studies, the spread of periodontal tissue diseases has tendency to increase, despite recent decades' significant achievement in dentistry. [1, 2] Many studies are devoted to the study of periodontal tissue diseases pathogenesis. It was found that oxygen-dependent production of reactive oxygen species (ROS) and antioxidant activity are involved in the pathogenetic mechanism of the disease. [3]

ROS include free radicals that are derivatives of oxygen, namely: superoxide $\left(\mathrm{O}_{2-}\right)$, hydroxyl $\left(\mathrm{OH}_{-}\right)$, nitric oxide (NO), hydrogen peroxide $\left(\mathrm{H}_{2} \mathrm{O}_{2}\right)$ and hypochloride acid (HOCl) $[4,5]$. ROS are highly toxic, not only to the intracellular microbial agent but also to the extracellular structure and can induce lipid peroxidation (LPO) [5, 6]. Excessive production of LPO can lead to oxidative stress, thereby damaging the integrity of the cells.

As LPO is a result of oxidative stress, numerous markers are used to monitor this process. Malonic dialdehyde (MDA) and diene conjugates (DC) are the main and most studied products of polyunsaturated fatty acid peroxidation, which indicate an oxidative stress increase $[3,7,8]$.

Antioxidants, many of which are released locally in inflammation areas caused by polymorphonuclear leukocytes or other cells, can provide protection against ROS. In healthy organisms, the balance is maintained by the interaction of oxidants and antioxidants. In pathological conditions, the balance can be directed towards oxidants. The most significant antioxidant is superoxide dismutase (SOD), which catalyzes dismutation of $\mathrm{O}_{2-}$ to $\mathrm{H}_{2} \mathrm{O}_{2}$ and $\mathrm{O}_{2}[3,9,10]$.

In recent years, attention has been paid to the role of ROS, antioxidant systems, oxidative stress products, and LPO in periodontal tissues diseases pathology. Possible connection of oral fluid antioxidant system disorser and increase of oxidative stress in generalized periodontitis (GP) has been investigated [11, 12].

Studies by scientists (Tsai C.C., Chen H.S., Chen S.L., et al.) have shown an increased level of LPO in generalized periodontitis patients [13]. "Noofen" is one of the medicines that normalizes the processes of LPO and shows positive effect in GP treatment. That is why in advanced complex treatment of generalized periodontitis of initial-I stage, we used this drug.

\section{The objective of the study}

To analyze the efficiency of nootropic medicine "Noofen" usage in complex initial-I stage generalized periodontitis treatment, taking into account the dynamics of oral fluid prooxidant and antioxidant indicators among students with high level of emotional sensitivity.

\section{Materials and Methods}

To achieve this goal, 174 students of the $2^{\text {nd }}$ year of study of Ivano-Frankivsk National Medical University were questioned in order to determine the level of individual emotional states (anxiety, frustration, aggression and rigidity) according to the method of H. Eysenck. Of those who have experienced increased and high levels of emotional sensitivity to various stressors and situations, we have selected 50 students with initial-I stage of generalized periodontitis. To determine the efficiency of treatment, two groups were formed: observation (group I) and comparison (group II). Each group consisted of 25 individuals who were treated and monitored dynamically during the year.

The students of group I had advanced treatment, which included oral sanitation, professional hygiene with hygienic skills training, local treatment - oral rinsing with "Octenisept" solution and dissolving of tablets "Lizak". For general treatment, patients of this group received a nootropic medicine "Noofen". Students of group II received usual treatment according to a dental care protocol, which included sanitization and professional hygiene of the oral cavity with hygienic skills training, local treatment - oral rinsing with $0.05 \%$ chlorhexidine solution and dissolving of the tablet "Lisobakt". Patients in both groups received the vitamin-mineral premix "Vita-Supradin Active".

To make the diagnosis of initial-I stage generalized periodontitis, we've used the data of objective 


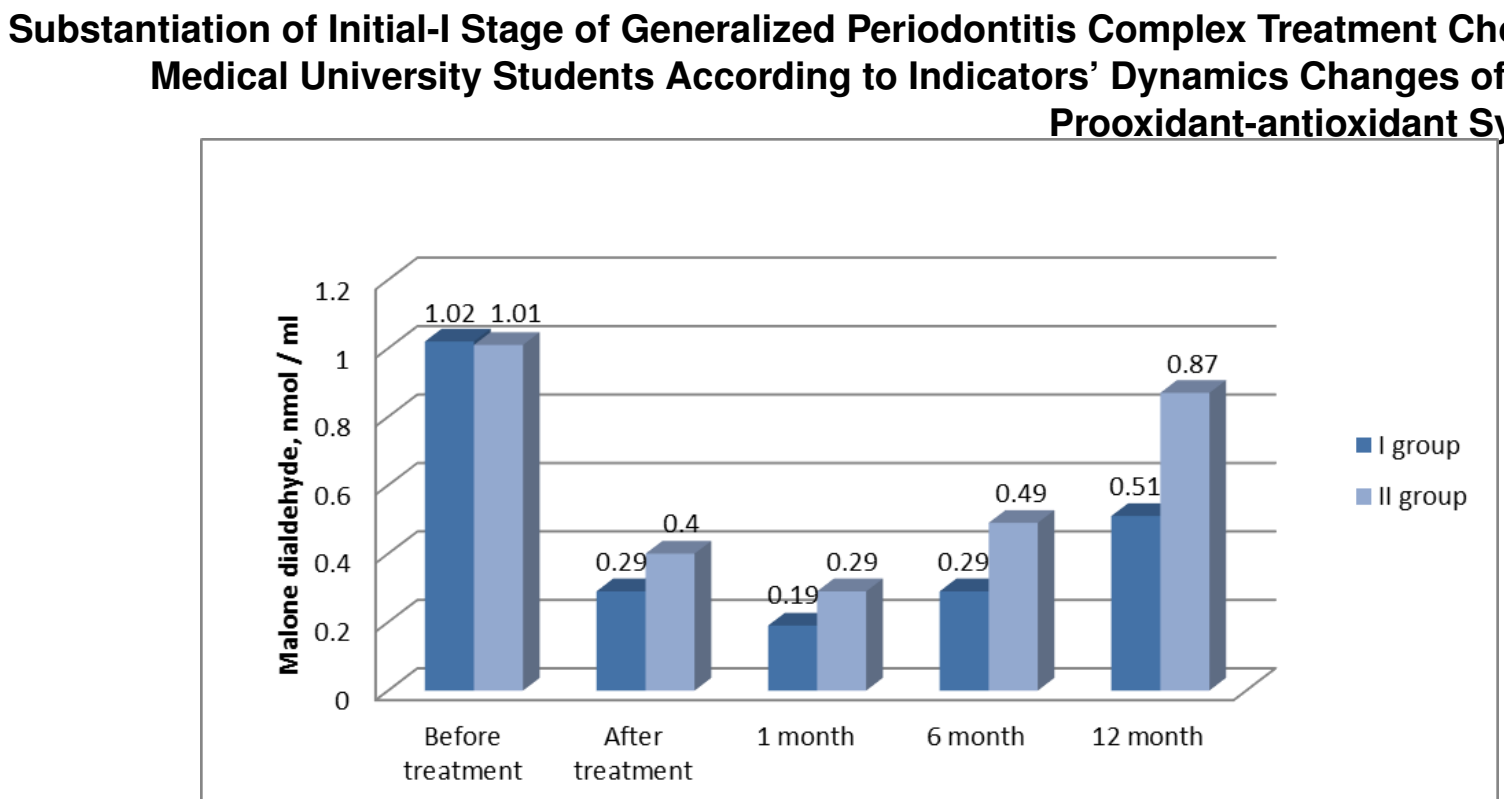

Figure 1. Dynamics of malone dialdehyde index changes during treatment stages.

examination, clinical indicators of hygienic and periodontal indices, as well as M.F. Danilevsky periodontal tissues diseases classification [14].

To evaluate prooxidant-antioxidant system condition in students with GP there was performed a study of oral fluid, which was taken in the morning. The condition of oral cavity prooxidant system was determined according to the level of malondialdehyde (MDA) and diene conjugates (DC). To study the state of the antioxidant protection system, the activity of superoxide dismutase (SOD), glutathione-S-transferase (G-ST) and glutathione peroxidase (GPO) were determined [15, 16, 17].

Clinical and laboratory examination were performed before treatment, immediately after the treatment, after 1 month, 6 months, and 12 months of therapy.

The obtained data was processed using the statistical package "Stat Soft 6.0", the classical methods of variation statistics. The differences between the studied indicators were estimated according to the Student's criterion.

\section{Results and Discussion}

The dynamics results of MDA changes treatment (Fig. 1) indicate that before treatment this indicator was approximately the same in groups I and II and measured $1.02 \pm 0.09$ and $1.01 \pm 0.08 \mathrm{nmol} / \mathrm{ml}$. ( $\mathrm{p}>0.05)$. However, after the performed treatment,
MDA decreased to $0.29 \pm 0.03 \mathrm{nmol} / \mathrm{ml}$ in group I, which is statistically lower than in group II $\mathrm{MDA}=0.4 \pm 0.04 \mathrm{nmol} / \mathrm{ml}(\mathrm{p}<0.001)$. Observing the MDA level one month after treatment, this indicator decreased in both groups $(\mathrm{p}<0.001)$. After 6 and 12 months, this value was gradually increasing in groups I and II, although it was statistically lower in group I than in group II.

Analyzing the data of DC (Fig. 2), we can also see that before the treatment they were practically the same ( $p>0.05)$, and immediately after the treatment they practically did not differ in both groups $(\mathrm{p}>0.05)$. However, after 1 month, DC data differed significantly in groups I and II and were $0.19 \pm 0.03$ and $0.33 \pm 0.01$ c.u., respectively $(\mathrm{p}<0.001)$. After 6 months, this indicator increased in both groups, but in group I the number of DC was significantly lower than in group II $(\mathrm{p}<0.001)$. After 12 months, the number of DC in group II increased to $0.5 \pm 0.02$ c.u., which was not significantly different from the indicator before the treatment ( $\mathrm{p}>0.05)$, and in group I this value though increased to $0.36 \pm 0.03$ c.u., but was statistically lower than before the treatment $(\mathrm{p}<0.001)$.

Considering the concentration of SOD in the oral fluid (Fig. 3), we can see that after the treatment in both groups, this value was almost the same ( $p>0.05)$. However, within a month, the concentration of SOD began to decrease and within a year in 


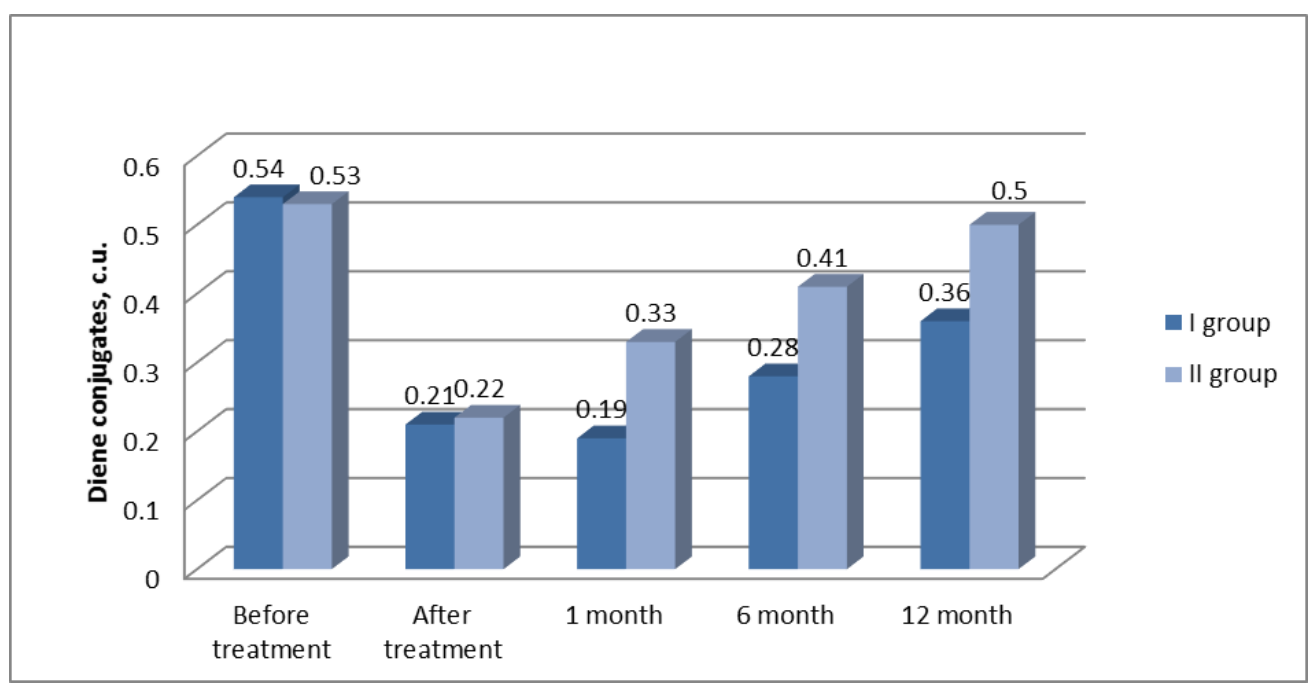

Figure 2. Dynamics of diene conjugates index changes during the treatment stages.

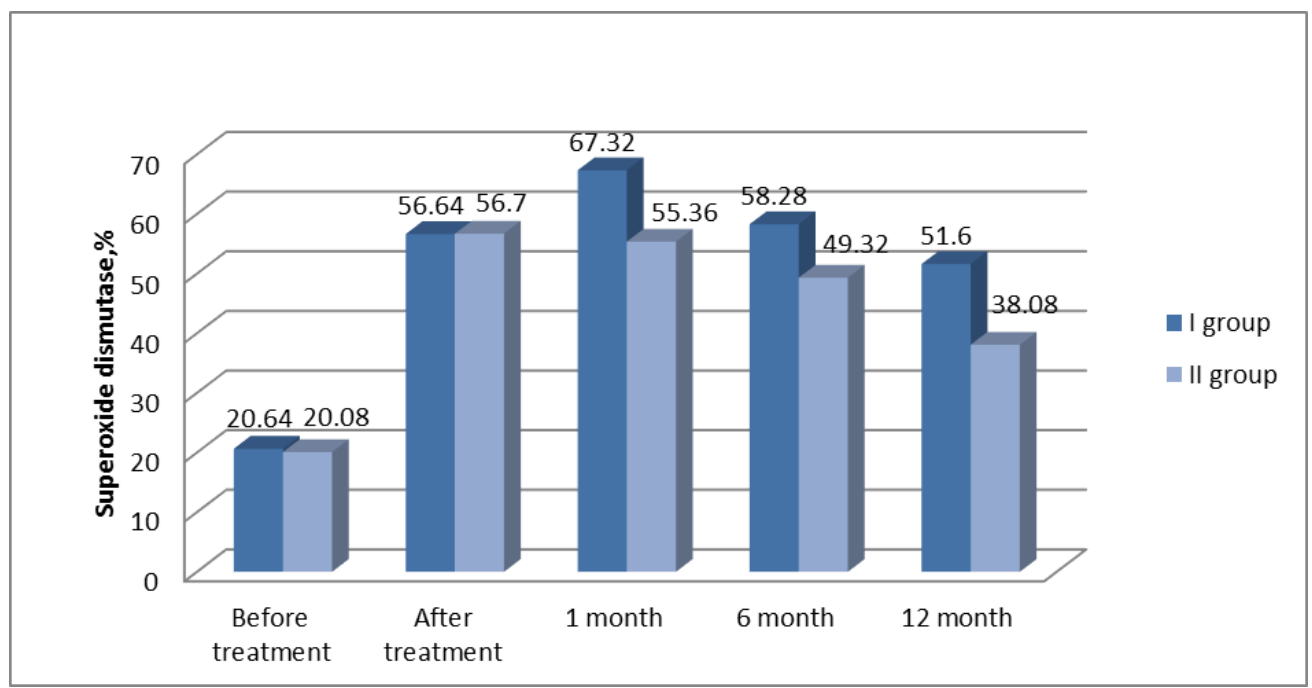

Figure 3. Dynamics of superoxide dismutase index changes at the stages of treatment.

the group II it was $38.08 \pm 2.53 \%$. In group I, this indicator was more stable, and in one year after the treatment it was $51.6 \pm 2.44 \%$, which was statistically better than in group II $(\mathrm{p}<0.001)$. Moreover, in group I the long-term data (after 12 months) are virtually indistinguishable from those obtained immediately after the treatment.

Evaluating the G-ST index (Fig. 4), we've observed that after the treatment it improved significantly in both groups $(\mathrm{p}<0.001)$, but in group I it was significantly better than in group II $(\mathrm{p}<0.001)$. After the treatment, the index values gradually decreased, although in group I one year after the treat- ment it corresponded to $8.69 \pm 0.6 \mathrm{nmol} / \mathrm{min} * \mathrm{mg}$, which was significantly better than in group II $(\mathrm{p}<0.001)$.

With regard to the GPO index (Fig. 5), its level in groups I and II after the treatment improved significantly $(\mathrm{p}<0.001)$, although in group I the indicator was statistically better compared to group II $(\mathrm{p}<0.001)$. In dynamics after the performed treatment, the indices of both groups gradually decreased, but the data of group I were significantly higher than in group II $(\mathrm{p}<0.001)$. 


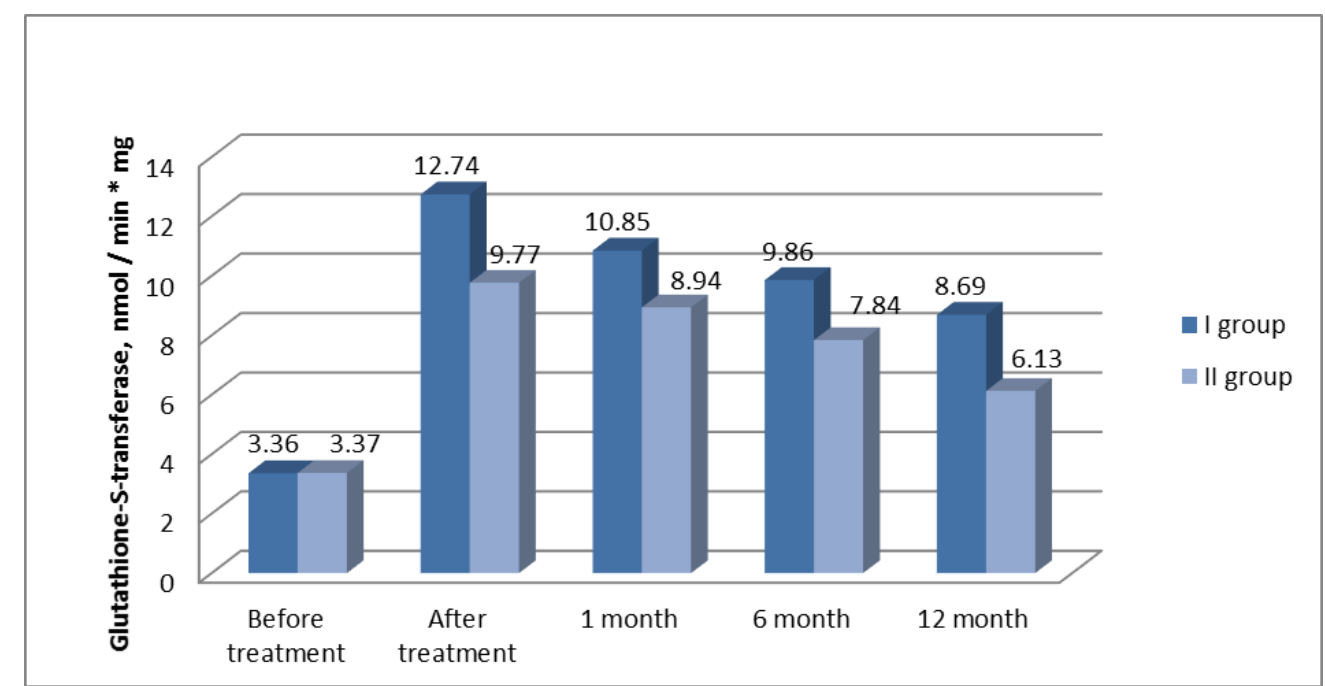

Figure 4. Dynamics of glutathione-S-transferase index changes in the treatment stages.

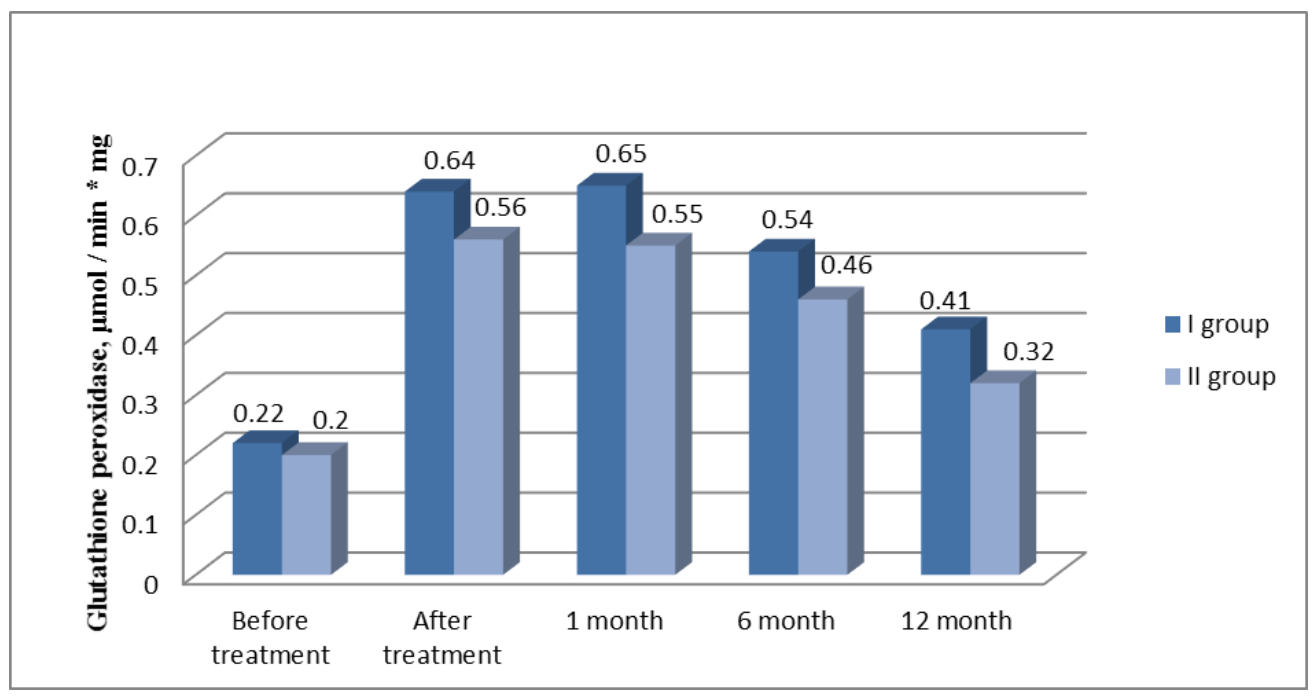

Figure 5. Dynamics of glutathione peroxidase index changes during the treatment stages.

\section{Prospects of Further Researches}

We plan to study further the effect of advanced therapy in students of the third, forth and fifth year of study of medical university with initial-I stage of GP, who were performed the treatment of periodontal tissue diseases according to the advanced methods.

\section{Conclusions}

The use of advanced treatment of GP, which included nootropic medicine "Noofen", antiseptic mouthwash - "Octenisept" and dissolving of tablet "Lizak" in complex treatment of GP in the $2^{\text {nd }}$ year medical university students with high level of emotional sensitivity, that is confirmed by the biochemical parameters of the oral fluid. Indicators of prooxidant-antioxidant system in group I undergoing advanced treatment, were more stable and better in the long term compared with group II $(\mathrm{p}<0.001)$, where conventional therapy was used. 


\section{References}

[1] Kholodnyak OV, Dobrovolskaya MK. The effectiveness of treatment of localized periodontal tissue diseases in young people according to the study of the rate of salivation and acid-base balance in the oral cavity. Clinical dentistry. 2015; 3-4: 46-52. [published in Ukrainian]

[2] Slootweg PJ. Dental pathology. Springer; 2007. 83 p. DOI: https://doi.org/ $10.1007 / 978-3-540-71691-4$ [PMCid:PMC2807505]

[3] Wei D, Zhang X-L, Wang Y-Z, Yang C-X, $\mathrm{G}$ Chen. Lipid peroxidation levels, total oxidant status and superoxide dismutase in serum, saliva and gingival crevicular fluid in chronic periodontitis patients before and after periodontal therapy. Australian Dental Journal. [Internet]. 2010 March. DOI: https://doi.org/10. $1111 / j .1834-7819.2009 .01123 . x$ [PMid:20415915]

[4] Canakci CF, Cicek Y, Canakci V. Reactive oxygen species and human inflammatory periodontal diseases. Biochemistry (Mosc). [Internet]. 2005 Jun;70:619-628. DOI: https://doi.org/10.1007/ s10541-005-0161-9 [PMid:16038603]

[5] Waddington RJ, Moseley R, Embery G. Reactive oxygen species: a potential role in the pathogenesis of periodontal diseases. Oral Dis. [Internet]. 2000 May;6(3):138-151. DOI: https://doi.org/10.1111/ j.1601-0825.2000.tb00325.x

[PMid:10822357]

[6] Ornoy A. Embryonic oxidative stress as a mechanism of teratogenesis with special emphasis on diabetic embryopathy. Reprod Toxicol. [Internet]. 2007 Jul;24(1):31-41. DOI: https : / / doi . org / $10.1016 /$ j.reprotox.2007.04.004 [PMid:17548185]
[7] Del Rio D, Serafini M, Pellegrini N. Selected methodologies to assess oxidative/antioxidant status in vivo: a critical review. Nutr Metab Cardiovasc Dis. [Internet]. 2002 Dec;12(6):343351 .

[8] Del Rio D, Stewart AJ, Pellegrini N. A review of recent studies on malondialdehyde as toxic molecule and biological marker of oxidative stress. Nutr Metab Cardiovasc Dis. [Internet]. 2005 Aug;15(4):316-328. DOI: https://doi.org/10.1016/j. numecd.2005.05.003 [PMid:16054557]

[9] Manasa Ambati, Koduganti Rekha Rani, Panthula Veerendranath Reddy, Jammula Suryaprasanna, Rajashree Dasari, Himabindu Gireddy. Evaluation of oxidative stress in chronic periodontitis patients following systemic antioxidant supplementation: A clinical and biochemical study. J Nat Sci Biol Med. [Internet]. 2017;8(1):99-103. DOI: https://doi.org/10.4103/ $0976-9668.198366$

[PMid:28250683 PMCid:PMC5320832]

[10] Valko M, Leibfritz D, Moncol J, Cronin MT, Mazur M, Telser J. Free radicals and antioxidants in normal physiological functions and human disease. Int $\mathrm{J}$ Biochem Cell Biol. [Internet]. 2007;39(1):44-84. DOI: https://doi.org/10.1016/j. biocel.2006.07.001 [PMid:16978905]

[11] Canakci V, Yildirim A, Canakci CF, Eltas A, Cicek Y, Canakci H. Total antioxidant capacity and antioxidant enzymes in serum, saliva, and gingival crevicular fluid of preeclamptic women with and without periodontal disease. J Periodontol. [Internet]. 2007;78(8):1602-1611.DOI: https : / / doi . org/10.1902/jop.2007.060469 [PMid:17668980]

[12] Chapple IL, Brock GR, Milward MR, Ling N, Matthews JB. Compromised GCF total antioxidant capacity in periodontitis: cause or effect? 
J Clin Periodontol. [Internet]. 2007;34(2):103-

110. DOI: https://doi.org/10. $1111 / j .1600-051 \mathrm{x} .2006 .01029 . \mathrm{x}$

[PMid:17214737]

[13] Tsai CC, Chen HS, Chen SL, Ho YP, Ho $\mathrm{KY}, \mathrm{Wu} \mathrm{YM}$ et al. Lipid peroxidation: a possible role in the induction and progression of chronic periodontitis. J Periodontal Res. [Internet]. 2005;40(5):378384. DOI: https://doi.org/10. $1111 / j .1600-0765.2005 .00818 . x$

[PMid:16105090]

[14] Danilevsky MF, Borisenko AB, Politun AM, Antonenko MJ, Siedelnikova LF, Nesin OF. Therapeutic dentistry. Book 3, Periodontal Disease. Kyiv: Medicine; 2008. 614s. [published in Ukrainian]

[15] Magalyas VM, Mikheyev AO, Horny SE. Modern Methods of Experimental and Clinical Research at the BSMA Central Research Laboratory. Chernivtsi: BDMA 2001. 42s. [published in Ukrainian]

[16] Gerush IV, Meshchishen IF. The state of the glutathione blood system under experimental ulcerative lesions of the gastroduodenal zone and the action of tincture of purple echinacea. Bulletin of problems of biology and medicine. 1998; 7: 10-15. [published in Ukrainian]

[17] Godovanets OI. Long-term results of the use of antioxidant drugs in the treatment of chronic catarrhal gingivitis in children. The world of medicine and biology. 2012; 3: 80-83. [published in Ukrainian]

Received: $2019-08-28$

Revised: $2019-10-23$

Accepted: $2019-10-28$ 